REVISTA DE

$\bigcup_{\text {ISSN }}^{\text {R717-5051 }}$ BNISMO

http://revistaurbanismo.uchile.cl

\title{
La Ciudad es un reto para la democracia
}

The City is a challenge for democracy

Israela Rosenblum

\section{Filiación}

Arquitecto-Urbanista, Presidenta de la Comisión de Desarrollo Urbano y Medio Ambiente del Colegio de Arquitectos de Chile, A.G.

\section{Resumen}

Discurso el Día Mundial del Urbanismo, en acto oficial realizado el 8 de noviembre de 1999, en la terraza Caupolicán del Cerro Santa Lucía de Santiago de Chile.

Palabras clave

Día Mundial del Urbanismo - Chile, Israela Rosenblum.

\begin{abstract}
Israela Rosenblum's speech on World Town Planning Day. Official ceremony held on November 8, 1999 on the terrace Caupolicán, Cerro Santa Lucia Santiago de Chile.
\end{abstract}

\section{Key words}

World Town Planning Day, Israela Rosenblum.

\section{Sumario}

[La ciudad es un reto para la democracia]

[En los albores del próximo siglo]

[Una política de participación ciudadana]

[Candidatos a la Presidencia de la República y políticas urbanas]

[El medio ambiente, una variable fundamental] 


\section{[La ciudad es un reto para la democracia]}

\section{Señores:}

Ministro de la Vivienda y Urbanismo de Chile, Presidente del Colegio de Arquitectos de Chile, Decano de la Facultad de Arquitectura y Urbanismo de la Universidad de Chile, arquitectos, urbanistas, ciudadanos, amigos:

"La ciudad es un reto para la democracia" es nuestra declaración al celebrar los cincuenta años del Día Mundial del Urbanismo. Es por ello debemos iniciar una nueva etapa de comunicación y compromiso.

En primer lugar, daremos nuestro marco conceptual que venimos elaborando hace muchos años la Comisión de Desarrollo Urbano y Medio Ambiente del Colegio de Arquitectos $y$, en segundo término, daremos a conocer un resumen de las posturas que tienen los candidatos a la Presidencia de la República sobre la materia.

Históricamente las ciudades han desempeñado un papel fundamental en la configuración de la identidad cultural, económica y social.

En el presente siglo, el proceso urbano, el crecimiento de las ciudades y en especial la ciudad de Santiago, se ha consolidado como motores económicos al atraer la concentración de nuevas actividades relacionadas con el conocimiento, la innovación y la cultura.

En concreto, el aumento del protagonismo económico de esta metrópolis se ha debido a múltiples factores entre los cuales podemos destacar el crecimiento de la economía, la oferta de oportunidades de empleo, los beneficios de la concentración, el acceso a la instrucción y cultura, los avances de los sistemas industriales de producción, la modernización de las infraestructuras, del transporte, los avances en el sector de las telecomunicaciones, entre otros.

Sin embargo, este crecimiento no fue planificado oportunamente, ya que podemos observar que el $40 \%$ de la población del país vive en la Región Metropolitana de Santiago, donde hay segregación social, aumento de la contaminación y polución, falta de áreas verdes. Con el expansionismo urbano se ha depredado los suelos agrícolas, hay problemas calidad de la salud mental, la política de construir más cantidad de casas, lo que llamamos "el viviendismo", sin una planificación previa ha producido carencia de áreas verdes, equipamientos y servicios complementarios, etc. 


\section{[En los albores del próximo siglo]}

Los albores del próximo siglo presentan un panorama de profundas transformaciones que se vienen sucediendo con gran vertiginosidad. No resulta fácil percibir a simple vista, ni mucho menos dimensionar, los impactos que estos cambios generarán sobre los asentamientos humanos.

El avance tecnológico de las comunicaciones y del transporte, la apertura del comercio, la internacionalización de la economía, la creativa organización industrial, los nuevos procesos productivos, la globalización de la información y comunicación, los traspasos de las fronteras nacionales que se están produciendo en el proceso de integración del Mercosur, ponen en tensión las identidades propias de cada país; la competitividad de las ciudades deberá ofrecer mejor calidad de vida y seguridad para atraer a inversionistas, turistas, centros administrativos y financieros, etc.

La ciudad como espacio político, económico y cultural debe ser el espacio de las sinergias económicas y de la competitividad, pero también el desafío debe ser para la cohesión social y con un medio ambiente sustentable.

El urbanismo como estética se mide por la calidad de los espacios públicos y por su capacidad de promover dinámicas transformadoras y articuladoras del tejido urbano. El espacio público promociona significativamente la vida urbana y confiere a la ciudad el atributo de dar sentido a sus habitantes. El urbanismo tendrá virtud democrática si asume, explicita y desarrolla un proyecto de ciudad.

En este marco conceptual, hay una gran labor que debemos realizar todos los actores involucrados en el hacer ciudad. El sector público y el sector privado deben deponer sus desconfianzas mutuas, debiendo coordinarse para realizar grandes proyectos que requieren actuaciones integradas y complejas.

El sector público debe definir objetivos, reglas y normativas, una estrategia, un catálogo de actuaciones iniciales y unos interlocutores válidos para negociar con los agentes privados. Todo este proceso debe darse en un marco de trasparencia política y simplicidad administrativa. Valoramos el esfuerzo que está haciendo actualmente el Ministerio de la Vivienda y Urbanismo con la modificación de la Ley General de Urbanismo y Construcciones y de la Ordenanza, oyendo a los principales actores de este quehacer urbano.

Las universidades también tienen un rol fundamental que realizar, cual es capacitar a las nuevas generaciones de urbanistas, hacer extensión de sus conocimientos a la ciudadanía en general, y lo más importante, soñar la ciudad que queremos entregando estudios, conocimientos, indicadores e instrumentos para que la sociedad pueda alcanzar esa utopía. 


\section{[Una política de participación ciudadana]}

La valoración positiva de los proyectos urbanos incluyendo los instrumentos de planificación en todos sus niveles, dependerá de la fuerza que adquieran en el debate de los mismos los distintos sectores sociales. Esto conlleva a definir una política de participación ciudadana y llevar a cabo programas intersectoriales destinados a crear, mejorar y estimular el los encuentros públicos; se exige niveles de mutua confianza, respeto a la pluralidad de ideas y diversidad de concepciones culturales de la vida en sociedad.

Según el Premio Nacional de Ciencias, Humberto Maturana, "es necesario cultivar la participación con la formación del ser. Tenemos que cultivarla desde la infancia, desde los niños pequeños. Eso se aprende y se cultiva, y si no se cultiva se pierde, y cuando se pierde se entra en la depresión, y en ese estado no hay posibilidad de convivencia democrática".

Sin embargo, la participación posee también otra connotación muy importante para el desarrollo de las ciudades, cual es la de constituirse en un instrumento técnico insustituible a la hora de concebir métodos o formas de planificación, cuyas expresiones son los planes de variado tipo que ahora están a disposición de los urbanistas. Hoy día un proceso de planificación carente de participación es algo difícilmente sostenible y de imposible práctica. Podemos enumerar diversos ejemplos que lo demuestran.

Por primera vez se está discutiendo en el seno del Congreso Nacional la modificación de la Ley General de Urbanismo y Construcciones, donde el Colegio de Arquitectos expuso a la Comisión de Vivienda de la Cámara de Diputados su principal observación respecto a la incorporación de una mayor participación ciudadana en el proceso de elaboración de los distintos instrumentos de Planificación. No es fácil este tema, pero debemos abordarlo con madurez y generosidad.

Las organizaciones sociales, territoriales, funcionales, vecinales, culturales, los entes académicos, o técnicos, los económicos y gremiales, las ONG'S, deben reivindicar su derecho a la información desde el inicio del proceso, a demandas y críticas, a elaborar informe y propuestas, a recibir explicaciones y respuestas, y a tener un lugar relevante en espacios de negociación. Pero esto no exime a los políticos de la responsabilidad de tomar decisiones, primero para definir objetivos y proyectos, y luego para mediar si es necesario, y asumir los costos de la decisión final.

Hace muchos años que venimos sosteniendo que el urbanismo no está en la agenda de los políticos, y convencidos que este tema nos afecta a todos los que vivimos en la ciudad, la Comisión de Desarrollo Urbano y Medio Ambiente del Colegio de Arquitectos juzgó conveniente en este año de elecciones presidenciales, convocar a todos los candidatos y candidatas a la Presidencia, a pensar en la ciudad, dándole la relevancia que se merece dentro de sus agendas políticas, exponer sus puntos de vista respecto al Desarrollo Urbano y Medio Ambiente, y definiciones en temas ligados a ellas. 


\section{[Candidatos a la Presidencia de la República y políticas urbanas]}

Nos honraron con su presencia el Sr. Hirsch, la Sra. Larraín y el Sr. Lagos. La Sra. Marín y el Sr. Lavín remitieron en sendos documentos sus planteamientos programáticos. El Sr. Arturo Frei excusó su participación.

Después de esta convocatoria podemos afirmar, no sin sorpresa y sí con mucha alegría, que hoy día las personas que aspiran a ejercer la primera magistratura poseen una idea de ciudad y contemplan en sus programas lineamientos de políticas urbanas $y$, lo que es más sorprendente, comparten con los urbanistas algunas inquietudes básicas en torno al tema.

Al celebrar los cincuenta años del Día Mundial del Urbanismo, la Comisión ha querido exponer - por mi intermedio - algunas ideas de estos discursos de las candidatas y candidatos presidenciales, en el convencimiento que estas miradas a futuro están acompañadas de voluntades políticas que servirán para modelar nuevas formas de enfrentar los desafíos urbanos. Los documentos completos están disponibles en el Colegio de Arquitectos, para los profesionales interesados en la materia.

No podemos ni queremos decir que estas cinco personalidades piensan lo mismo en torno a estos tópicos; no obstante, todos exhiben un marcado interés en mostrar una posición política en torno a ellos, posición que - por supuesto - tiene su base en concepciones políticas que rebasan lo meramente urbano. Nuestro análisis, en consecuencia, iguala en el marco de las preocupaciones e inquietudes, respetando las diferencias que identifican a cada candidata y candidato.

La idea que estimamos más importante - y que se pasea por el discurso de casi todos es sin duda la aspiración de que la ciudadanía ejerza plenamente la participación en el desarrollo urbano. Se piensa que la participación es consustancial a la forma política democrática, en contraposición con la imposición que está asociada a las formas autoritarias. Así vistas las cosas, la participación debe ser considerada un derecho al que todo ciudadano aspira, de tal modo que le permita, ejerciendo y desarrollando su libertad, con responsabilidad, ser protagonistas de su propia historia, de su barrio, de su comuna y de su ciudad.

Aquí también cabe referirse a la definición política de cada uno respecto a cuál es el rol le corresponde a cada uno de los actores urbanos para poder participar del Estado, de los inversionistas del sector privado, y de la comunidad con sus organizaciones. El rol y la importancia que se le asigne a cada uno de estos sectores, definen de algún modo el carácter y la identidad de cada candidatura en este aspecto. Tenemos, pues, el papel que debe jugar cada uno de los sectores y de qué modo participar en el proceso de planificación de las ciudades. 


\section{[El medio ambiente, una variable fundamental]}

Otro tema central del cual se ocuparon nuestros personajes es el del medio ambiente, asunto de carácter prioritario cuando debemos establecer orientaciones políticas para el sector del urbanismo. El medio ambiente es una variable fundamental que debe estar presente, como elemento sustantivo, en los procesos de planificación. No es posible seguir depredando nuestro territorio. No podemos permitir que la contaminación, en sus variadas formas se convierta en el impedimento más grave para el equilibrio del sistema.

Nuestro país ha realizado enormes esfuerzos en el último tiempo para compatibilizar el medio ambiente con la actividad del hombre, lo que se expresa en leyes e instituciones dirigidas a estos propósitos; sin embargo, estamos en las primeras fases de un proceso largo y complejo, con pocos recursos económicos y profesionales.

Otros tema que candidatos han juzgado de gran importancia es el gobierno de una metrópolis cuando está conformada por varias comunas como Santiago, Concepción y Valparaíso. En todas ellas es evidente que hay elementos que rebasan los límites comunales, tales como el transporte y la infraestructura sanitaria, la producción de basuras (que está cambiando nuestro paisaje), la polución del aire, etc. Es también evidente que falta una mano que las organice y dirija a partir de políticas claras y de una planificación en el ámbito de una gran ciudad, lo que no quiere decir que no se respeten las características locales de cada comuna.

El asentamiento institucional del urbanismo, es otro de los temas tocado en que éste no sólo se encuentra radicado en el Ministerio de Vivienda y Urbanismo sino también lo norman, el de Obras Públicas, el de Agricultura, el de Transportes y Telecomunicaciones, el de Bienes Nacionales, Mideplán, el Ministerio Secretaría General de Gobierno, los Gobiernos Regionales, Conama, el Sesma, las Municipalidades, etc.

Se trata, en último término, de la estructura de la institucionalidad del urbanismo y otros temas conexos y afines que es necesario analizar y definir, buscando una mayor funcionalidad en el marco de este fin de siglo. Con estos propósitos algunas candidaturas proponen crear nuevos ministerios y fusionar otros, asunto que a la vez de delicado es de gran complejidad.

Otro tema recurrente en todas las candidaturas analizadas, es el que tiene que ver con la seguridad de los ciudadanos desde la óptica urbana, llegando a sostener que los espacios públicos bien concebidos y tratados pueden constituir la base de nuestra futura seguridad.

La Comisión de Desarrollo Urbano y Medio Ambiente del Colegio de Arquitectos mira con optimismo el futuro que se avecina. 


\section{REVSTADE \\ URBRANANISMO}

http://revistaurbanismo.uchile.cl

La Ciudad es un reto para la democracia

The City is a challenge for democracy

Hemos constatado el interés de nuestras futuras autoridades en torno a los tópicos urbanos, lo que se expresa en abundantes propósitos que antes no habíamos escuchado con ese grado de compromiso. Desde luego, estos propósitos deben transformarse en políticas concretas, normas, y directrices que permitan acciones relevantes, dentro de una real trasparencia y modernización administrativa para conseguir las nuevas realidades que el sector requiere.

Tenemos fe y esperanza en que el día de mañana nuestros nietos podrán mirar el cielo y cantar con propiedad los hermosos versos que aprendimos de niños: "Puro Chile es tu cielo azulado, / puras brisas te cruzan también / y ese campo de flores bordado/ ...

I.R. 